\title{
The Effects of Age on Pupil Diameter at Different Light Amplitudes
}

\author{
Dande Husniye Telek, ${ }^{1}$ (1) Hidayet Erdol, ${ }^{2}$ (D) Adem Turk ${ }^{2}$ \\ ${ }^{1}$ Department of Ophthalmology, Ankara Training and Researching Hospital, Ankara, Turkey \\ ${ }^{2}$ Department of Ophthalmology, Karadeniz Technical University Faculty of Medicine, Trabzon, Turkey
}

\begin{abstract}
Objectives: This study was an evaluation of pupil response at different light amplitudes in healthy individuals in different age groups.

Methods: A total of 210 eyes of 105 healthy individuals were included in the study. The participants were divided into 4 groups at 15-year age intervals: 15-30, 31-45, 46-60, and over 60 years. The dimensions of the pupil were measured with a pupillometer at 5 different light amplitudes: 0, I, 10, 100, and $200 \mathrm{~cd} / \mathrm{m}^{2}$. The average pupil diameter in the groups was compared and changes in pupil diameter were correlated for each light amplitude according to age.

Results: The mean pupil diameter was $4.96+0.82 \mathrm{~mm}$ in males, and $4.95+0.87 \mathrm{~mm}$ in females at $0 \mathrm{~cd} / \mathrm{m}^{2} \mathrm{light}$ amplitude, and $2.44+0.19 \mathrm{~mm}$ and $2.40+0.19 \mathrm{~mm}$, respectively, at $200 \mathrm{~cd} / \mathrm{m}^{2}$ light amplitude. The differences were not statistically significant $(p>0.05)$. In addition, there was no significant difference in pupil size between the right and left eye at any light amplitude $(p>0.05)$. Pupil diameters were found to be smaller at all light amplitudes with advanced age. There was a negative significant correlation between pupil size and age at all light amplitudes $(p<0.05)$. The correlation was stronger at low light amplitudes. Conclusion: Pupil response to light is influenced by age. This should be taken into consideration when evaluating pupil reaction.
\end{abstract}

Keywords: Electrophysiology, light amplitude, pupil diameter, pupil reaction.

\section{Introduction}

The iris regulates the amount of light reaching the retina by changing pupil diameter. Thus, it can decrease aberrations, increasing the depth of the focus by decreasing pupil diameter $(I, 2)$. The most influential factors on pupil diameter are the amplitude of the light reaching the retina and the accommodation made for near vision $(2,3)$. Several factors, such as age, attention level, changes in sympathetic and parasympathetic efferent pathways, and tone dominance, can be listed as other factors affecting pupil diameter $(I, 3)$.

Pupil diameter is very important for the quality of vision. A small pupil diameter allows for a clear image of high quality by decreasing spherical aberrations. The best retinal image for most eyes is obtained at a pupil diameter of 2.4 $\mathrm{mm}$, where the balance between aberration and diffraction is considered to be optimal (4-7). Campbell and Gregory (7) demonstrated that by adjusting the pupil diameter in a reflex manner in response to ambient light, one can achieve the most appropriate visual acuity.

The pupil functions via sympathetic and parasympathetic stimuli. Any pathology that appears in the pupil reflex arc distorts the light response by altering the adjustability of the pupil (I). The response to light can differ between healthy individuals. Pupil dimension can also be different in healthy individuals, and it decreases in size with advancing age. Compiling information about normal pupil response in different age groups and at different light amplitudes may add to a more objective evaluation of these responses.

\footnotetext{
Address for correspondence: Hande Husniye Telek, MD. Department of Ophthalmology, Ankara Training and

Researching Hospital, Ankara, Turkey

Phone: +90 3125953467 E-mail: handetelek@gmail.com

Submitted Date: January 30, 2018 Accepted Date: May 21, 2018 Available Online Date: July 14, 2018

${ }^{\circ}$ Copyright 2018 by Beyoglu Eye Training and Research Hospital - Available online at www.beyoglueye.com
} 
The participants in this study were divided into 4 subgroups and pupil diameter at 5 different light amplitudes was measured.

The aim of this study was to evaluate the pupil response at different light amplitudes in healthy individuals according to age group. Unlike other studies in the literature, it was observed that at advanced ages, especially under low illumination $\left(0\right.$ and $\left.\mathrm{I} \mathrm{cd} / \mathrm{m}^{2}\right)$, there was a slowing of the pupillary response.

\section{Methods}

This retroprospective study was performed at the Karadeniz Technical University Faculty of Medicine Ophthalmology Clinic between December 2009 and March 2009. All of the participants were informed about the study and their consent was obtained. The research was approved by the ethics committee of Karadeniz Technical University Faculty.

\section{Study Group}

To be eligible for the study the subjects had to fulfill the following criteria:

I. No previous history of ocular surgery,

2. Refractive error of \pm 1.00 diopters (D) range,

3. No visual defect,

4. Absence of any other systemic or ocular disease that might affect pupil response.

All the participants underwent a detailed ophthalmological examination (corrected visual acuity, biomicroscopic anterior-posterior segment examination, measurement of intraocular pressure). To evaluate the influence of age on pupil response, the cases in the study group were divided into 4 subgroups: 15-30 years (Group I), 3I-45 years (Group 2), 46-60 years (Group 3), and over 60 years (Group 4).

\section{Measurement Technique}

The participants were taken into a dark room in the electrophysiology unit in order to evaluate their pupil response. Measurements were carried out with a Monpack II (Metrovision, Pérenchies, France) electrophysiology device using the pupillometry mode. The measurements were performed both unilaterally and bilaterally. When measurements were made unilaterally, I eye of the participant was covered in order not to let in any light. After adapting to the dark environment ( 5 minutes), the computer automatically measured the pupil diameter in millimeters at light amplitudes of 0,1 , 10,100 , and $200 \mathrm{~cd} / \mathrm{m}^{2}$. Each light amplitude was applied for at least 10 seconds, with I-minute intervals between each measurement of the next intensity. The measurements were repeated 3 times for each light intensity level and the mean of all of the measurements was used as the final value.

\section{Statistical Evaluation}

The mean pupil size values obtained at 5 different amplitudes were separately compared within the group using Student's ttest. Pearson correlation analysis was used to evaluate whether age was correlated with pupil diameter at all light amplitudes. A p value of $<0.05$ was accepted as statistically significant.

\section{Results}

A total of 105 healthy individuals (49 male, 56 female) were admitted into the study. The mean age of the participants was $49.8+19.3$ years (range: 16-76 years). There was no significant difference between males $(49.8+18.3$ years) and females $(48.6+19.6$ years) in terms of age $(p>0.05)$. Pupil response was measured under both unilateral and bilateral illumination. No significant difference in pupil response was observed between males and females $(p>0.05)$. When the light amplitude increased from $0 \mathrm{~cd} / \mathrm{m}^{2}$ to $200 \mathrm{~cd} / \mathrm{m}^{2}$, pupil size decreased nearly $50 \%$ in all subjects.

The differences in pupil diameter obtained at different light amplitudes were compared, and there was no significant difference in the response from the left and the right eye in bilateral and unilateral illumination. Similarly, there was no significant difference between the right and the left eye at different illuminations $(p>0.05)$.

The mean bilateral and unilateral pupil size obtained according to amplitude is summarized in Table I.

Under unilateral illumination, the mean pupil diameter

Table I. The mean pupil size obtained in the right and left eye, bilaterally and unilaterally, at 5 different light amplitudes

Pupil size (Mean \pm SD)

\begin{tabular}{|c|c|c|c|c|}
\hline \multirow[b]{2}{*}{ Light amplitude $\left(\mathrm{cd} / \mathrm{m}^{2}\right)$} & \multicolumn{2}{|c|}{ Bilateral illumination } & \multicolumn{2}{|c|}{ Unilateral illumination } \\
\hline & Right eye & Left eye & Right eye & Left eye \\
\hline 0 & $4.67 \pm 0.84$ & $4.74 \pm 0.85$ & $4.96 \pm 0.82$ & $4.83 \pm 0.89$ \\
\hline I & $3.76 \pm 0.60$ & $3.85 \pm 0.67$ & $4.07 \pm 0.61$ & $4.07 \pm 0.76$ \\
\hline 10 & $2.88 \pm 0.53$ & $2.87 \pm 0.65$ & $3.37 \pm 0.58$ & $3.21 \pm 0.49$ \\
\hline 100 & $2.5 I \pm 0.38$ & $2.55 \pm 0.57$ & $2.70 \pm 0.44$ & $2.60 \pm 0.25$ \\
\hline 200 & $2.44 \pm 0.42$ & $2.47 \pm 0.51$ & $2.55 \pm 0.49$ & $2.44 \pm 0.19$ \\
\hline
\end{tabular}


was $4.96 \pm 0.82 \mathrm{~mm}$ in the right eye and $4.83 \pm 0.89 \mathrm{~mm}$ in left eye, while it was $4.67 \pm 0.84 \mathrm{~mm}$ and $4.74 \pm 0.85 \mathrm{~mm}$, respectively, with bilateral illumination at $0 \mathrm{~cd} / \mathrm{m}^{2}$ light amplitude. The differences were not statistically significant $(p>0.05)$. Although the pupil size was smaller with bilateral illumination than with unilateral illumination, the difference was not statistically significant $(p>0.05)$ (Table I). Pupil size was smaller by $4 \%$ to $6 \%$ under bilateral illumination compared with unilateral illumination. This difference was more obvious at $\mathrm{I}, 10$, and $100 \mathrm{~cd} / \mathrm{m}^{2}$ light amplitudes, whereas it was much smaller at $0 \mathrm{~cd} / \mathrm{m}^{2}$ and $200 \mathrm{~cd} / \mathrm{m}^{2}(1.45 \%$ and $2.11 \%$, respectively).

When the groups were compared, there was a statistically significant difference in pupil size at all light amplitudes between Group I (I5-30 years) and Group 4 (over 60 years) $(p<0.05)$. In particular, the difference at low light amplitudes was more obvious.

In a comparison of Group I with Group 2, the difference in pupil size was significant at $0, I$, and $10 \mathrm{~cd} / \mathrm{m}^{2}(p=0.03$, 0.02 , and 0.02 , respectively), while it was not significant at high light amplitudes $\left(100\right.$ and $\left.200 \mathrm{~cd} / \mathrm{m}^{2}\right)(p=0.16$ and 0.21 , respectively).

Likewise, when comparing Group I with Group 3, at 0, I, $10 \mathrm{~cd} / \mathrm{m}^{2}$ light amplitudes, there was a significant difference, whereas at 100 and $200 \mathrm{~cd} / \mathrm{m}^{2}$ light amplitudes, the difference was not significant.

No significant difference in pupil response at any light amplitude was seen in a comparison of Group 2 with Group 3 or between Group 3 and Group 4 ( $p>0.05)$. There was a significant difference only at $0 \mathrm{~cd} / \mathrm{m}^{2}$ light amplitude between Group 2 and Group 4 ( $p=0.00$ I). (Table 2)

When the correlation between pupil size and age was evaluated, a statistically significant negative correlation was observed at all light amplitudes. The statistical results were summarized in Table 3.

The correlation with increased age is stronger at low illuminations (Tables 2 and 3). At low light amplitudes, pupil diameter was smaller in the older participants.

\section{Discussion}

Pupillary light reflex appears at about 5 months postpartum and becomes active after 6 months. Pupil size is small during infancy; it becomes larger with age and reaches its maximum diameter in adolescence. It gradually decreases in the following years. The pupil has a diameter of $2.5-5.0 \mathrm{~mm}$ in normal individuals at rest. Pupil diameter is influenced by the age of the individual, psychogenic condition, and status of expirium or inspirium $(3,4)$. In this study, the pupil diameter of older adults was smaller at all light amplitudes compared with younger individuals.

The iris controls the amount of light entering the eye by dilating or contracting. Pupil diameter created by the iris can enlarge to $8 \mathrm{~mm}$ under dim light and decrease to $1.5 \mathrm{~mm}$ un-

Table 3. Correlation between illumination intensity and age

\begin{tabular}{lccccc} 
& \multicolumn{2}{c}{ Right eye } & & \multicolumn{2}{c}{ Left eye } \\
\cline { 2 - 3 } \cline { 5 - 6 } $\begin{array}{l}\text { Light amp- } \\
\text { litude }\left(\mathbf{c d} / \mathbf{m}^{2}\right)\end{array}$ & $\begin{array}{c}\text { Pearson } \\
\text { correlation }\end{array}$ & $\mathbf{P}$ & & $\begin{array}{c}\text { Pearson } \\
\text { correlation }\end{array}$ & $\mathbf{p}$ \\
\hline 0 & -0.60 & 0.000 & & -0.66 & 0.000 \\
1 & -0.40 & 0.000 & & -0.55 & 0.000 \\
10 & -0.33 & 0.000 & & -0.42 & 0.000 \\
100 & -0.31 & 0.001 & & -0.21 & 0.029 \\
200 & -0.31 & 0.001 & -0.22 & 0.022 \\
\hline
\end{tabular}

Table 2. The pupil diameter obtained in the right and left eye at different light amplitudes according to group

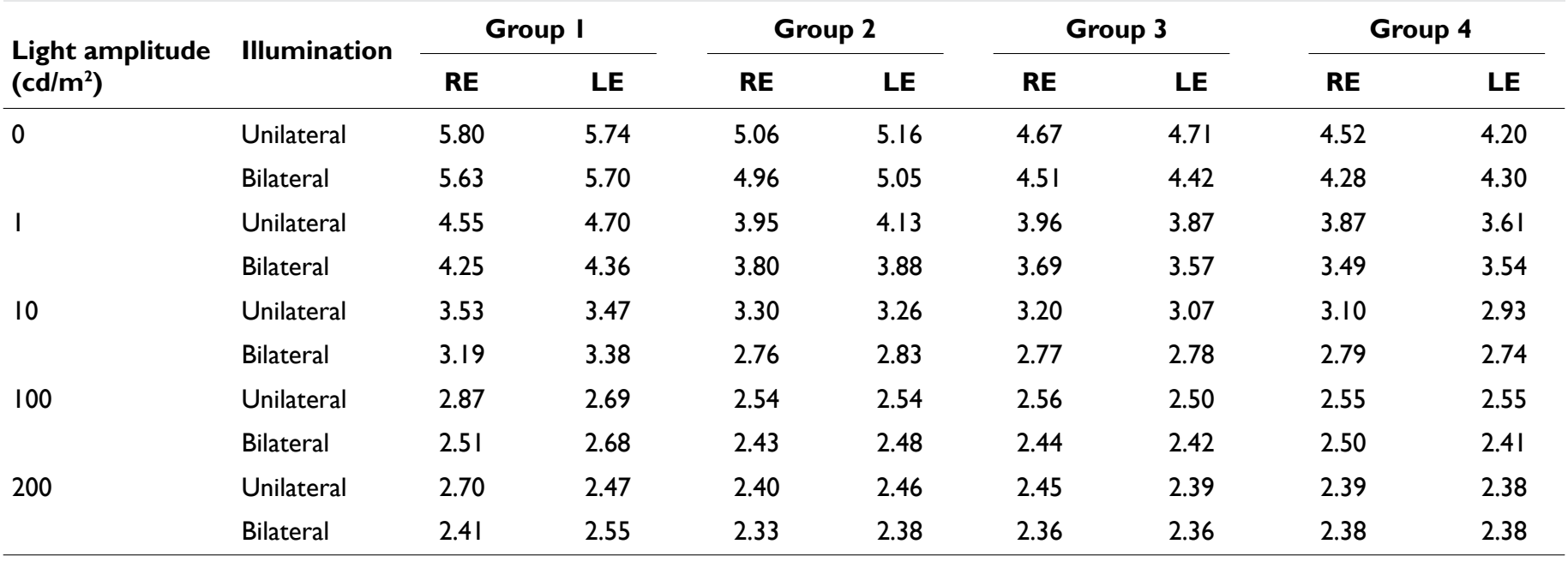

LE: Left eye; RE: Right eye. 
der very bright light. On a bright, sunny day, the light intensity is $34.260-103.000 \mathrm{~cd} / \mathrm{m}^{2}$ and there is maximal pupillary contraction. There is a strong relationship between pupil diameter and visual acuity. When background illumination was increased to $3400 \mathrm{~cd} / \mathrm{m}^{2}$, greater visual acuity has been demonstrated. When the eye is focused on a near object, pupil diameter decreases (4-6).

The pupil size of individuals with myopia is larger than that of individuals with emmetropia and hypermetropia. This is probably due to the fact that myopes do not need to make accommodation for near sight (I-6). In order to eliminate the discrepancies that might arise from errors of refraction, we excluded eyes with refractive errors outside $\pm I .00 \mathrm{D}$ range.

In recent years, various technologies have been developed to objectively evaluate pupil light reflex. Among these technologies, infrared videography and computerized pupillometry are most often employed (4-7). Pupil measurements in our study were carried out with the advanced Monpack II electrophysiology device using its pupillometry program.

Age is one of the most important factors affecting the activity and the shape of the pupil. Scotopic, mesopic, and photopic pupil diameters decrease with age. This decrease is thought to be due to the increased effort to accommodate to conditions seen at advanced ages, as accommodative capability decreases with age (8-15). Together with age, the shape of the pupil changes from a regular circular form to an irregular form. Pupil response is influenced by the initial pupil diameter, and the relationship between pupil response and the initial pupil diameter changes with age. The dynamics of pupillary response slow with age. Pupillary hippus at high frequencies also decreases with age. This means that the maximum speed of pupil contraction and dilatation decreases with age as well (16-18). Consistent with the data in the literature, the pupil diameter of elderly patients (Group 4) was smaller than that of the younger patients at all light amplitudes.

Glaucoma is a disease thought to affect pupil reactions; the dilatation speed of the affected eye is slower than that of the healthy eye. However, contraction speed is not influenced by this neuronal loss. No explanation has yet been found for this. Glaucoma patients are reported to have relative afferent pupillary defect (RAPD). Cataract is thought to affect light reactions through a different mechanism and results in less light reaching the retina. Cataract is reported to cause RAPD as well (19).

As in previous reports (20-25), we have shown that older people have a smaller resting pupil diameter in the dark than younger individuals. The reduction in darkness reflex amplitude and the prolongation of recovery time of the light reflex are consistent with the notion of a decrease in sympathetic activity occurring with old age. Such a mechanism may also explain the decline in resting pupil size with age. There is independent evidence that the sympathetic and parasympathetic components of the autonomic nervous system change differentially with age. Pagani et al. (26) reported that during tilt, aging is progressively associated with attenuation of the low frequency (sympathetic) component of the heart rate power spectrum, whereas the parasympathetic response to tilt, detectable in the high frequency band, is relatively well preserved.

The observed changes in static and dynamic characteristics of the pupil in older subjects are probably mediated by alterations in autonomic function, which may form part of a more general change in autonomic activity in old age. The precision and linearity of the decline of pupil size with age $(27,28)$ suggest that the pupillary system is very sensitive and most reliably reflects the normal aging process. It has been suggested that the decline in resting pupil size with age was due to senile iris degeneration leading to increased rigidity (25). Such a mechanism could perhaps account for a reduced light reflex amplitude or constrictive velocity, either directly or via a reduction in resting pupil size because of the floor effect mentioned earlier (29-33).

Older people have a reduced pupil diameter, consistent with a sympathetic deficit and/or parasympathetic disinhibition. There is reduced darkness reflex amplitude and dilatation velocity, consistent with a sympathetic deficit. Furthermore, older subjects have a prolonged pupillary light reflex recovery time, consistent with a sympathetic deficit (8). It has been reported that the dynamics of pupil responses are influenced by the biomechanics of the iris muscle plant (12). The form of the pupil also shows age-related change, presumably due to structural alterations (28), such as changes in the contractility of the muscle fibers, stromal atrophy with loss of connective tissue, and hyaline degeneration (9).

The physiological aspects of the effect of pupil size should be considered in terms of both behavioral and underlying neural mechanisms. Under photopic light levels, regulation of light flux is important; the pupil is small and demonstrates pupillary capture. With a step change in light level, there is a large gain in response and the pupil size change is maintained. The pupil is an effective (low pass) regulator. Gain, as first described for the pupil by Stark and Sherman (16), is the percentage change in aperture divided by the percentage change of light.

Under scotopic light levels it is less important for the pupil to regulate long-term light flux onto the retina; the pupil is large and demonstrates pupillary escape. With a step change in light level, the response has a smaller, but relatively high, gain for a brief period, and then with redilatation, the gain is greatly reduced, becoming almost insignificant. Thus, a large quantity of light can enter the eye in these mesopic and scotopic conditions. The pupil can only be considered a 
partial (or band pass) regulator for brief changes of light (I3). As mentioned in other studies, we have shown that pupil responses to light can be influenced by age. This should be taken into consideration when evaluating pupil reactions. There are studies about pupil reaction, but unlike other studies, we found that at advanced ages, especially under low illumination $\left(0\right.$ and $\left.\mathrm{I} \mathrm{cd} / \mathrm{m}^{2}\right)$, there is a slowing of the pupillary response.

In conclusion, advanced age affects pupil reaction. At advanced ages, especially under low illumination $(0$ and $\mathrm{I} \mathrm{cd} /$ $\mathrm{m}^{2}$ ), the pupillary response is slower. We think that more advanced electrophysiological studies are needed to identify the etiology behind differences in pupil diameter.

\section{Disclosures}

Peer-review: Externally peer-reviewed.

Conflict of Interest: None declared.

Authorship Contributions: Involved in design and conduct of the study (HHT, AT, HE); preparation and review of the study $(\mathrm{HHT}, \mathrm{HE})$; data collection $(\mathrm{HHT})$; and statistical analysis $(\mathrm{HHT})$.

\section{References}

I. Hedges TR, Friedman DI, Horton JC, Newman SA, Striph HGG. Pupil. In: Weingeist TA, Liesegang TJ, Grand MG, eds. Neuroophthalmology. San Francisco: American Academy of Ophthalmology, 2007: 97-100.

2. Glaser JS. The pupils and accommodations. In: Duane TD, Jaeger EA, editors. Clinical Ophthalmology. Philadelphia: Harper \& Row; 1984. p. I-5.

3. Bienfang DC. Neuroophthalmology of the pupil and accommodation. In: Albert DM, Jakobiec FA, editors. Principles and Practice of Ophthalmology. Philadelphia: W.B. Saunders; 1994. p. 2470-2.

4. Miller D. Light damage to the eye. In: Yanoff M, Duker JS, editors. Ophthalmology. 2nd ed. St Louis: Mosby; 2004. p. 4-5.

5. Miller D. Optic of the normal human eye. In: Yanoff M, Duker JS, editors. Ophthalmology. 2nd ed. St Louis: Mosby; 2004. p. I-2.

6. Kadron RH. The pupils. In: Yanoff M, Duker JS, eds. Ophthalmology, 2nd ed. St Louis: Mosby; 2004. p. I-4.

7. Campbell FW, Gregory AH. Effect of size of pupil on visual acuity. Nature 1960; 187: I I2I-3. [CrossRef]

8. Bitsios P, Prettyman R, Szabadi E. Changes in autonomic function with age: a study of pupillary kinetics in healthy young and old people. Age Ageing 1996;25:432-8. [CrossRef]

9. Loewenfeld IE. Age changes in pupillary diameter and reactions. In: Thompson SH, Daroff R, Frisen L, Glaser JS, Saunder MD, editors. Topics in neuro-ophthalmology. Baltimore: Williams \& Wilkins; 1979. p. 124-50.

10. Netto MV, Ambrósio R Jr, Wilson SE. Pupil size in refractive surgery candidates. J Refract Surg 2004;20:337-42.

I I. Yang Y, Thompson K, Burns SA. Pupil location under mesopic, photopic, and pharmacologically dilated conditions. Invest Ophthalmol Vis Sci 2002;43:2508-12.

12. Semmlow J, Hansmann D, Stark L. Variation in pupillomotor responsiveness with mean pupil size. Vision Res 1975;15:85-90.

13. Sun F, Tauchi P, Stark L. Dynamic pupillary response controlled by the pupil size effect. Exp Neurol 1983;82:3 I3-24. [CrossRef]

14. Usui S, Stark L. Sensory and motor mechanisms interact to control amplitude of pupil noise. Vision Res 1978; 18:505-7.

15. Kasthurirangan S, Glasser A. Age related changes in the characteristics of the near pupil response. Vision Res 2006;46:1393403. [CrossRef]

16. Kadlecova V, Peleska M, Vasko A. Dependence on age of the diameter of the pupil in the dark. Nature 1958;182:I520-I.

17. Schaeffel F, Wilhelm H, Zrenner E. Inter-individual variability in the dynamics of natural accommodation in humans: relation to age and refractive errors. J Physiol 1993;46I:30I-20. [CrossRef]

18. Kasthurirangan S, Glasser A. Characteristics of pupil responses during far-to-near and near-to-far accommodation. Ophthalmic Physiol Opt 2005;25:328-39. [CrossRef]

19. Kalaboukhova L, Fridhammar V, Lindblom B. Relative afferent pupillary defect in glaucoma: a pupillometric study. Acta Ophthalmol Scand 2007;85:5 I9-25. [CrossRef]

20. Ferrari GL, Marques Jefferson LB, Gandhi RA, Celia EJ, Tesfaye $S$, et al. An Approach to the Assessment of Diabetic Neuropathy Based on Dynamic Pupillometry. 29th Annual International Conference of the IEEE. Lyon, France Aug 22-26, 2007. Engineering in Medicine and Biology Society; 2007. p. 557-60

2I. Smith SA. Pupil function: tests and disorders. In: Bannister R, Mathias CJ, editors. Autonomic Failure. 3rd ed. Oxford: Oxford University Press; 1992. p. 393-4I2.

22. Smith SA, Dewhirst RR. A simple diagnostic test for pupillary abnormality in diabetic autonomic neuropathy. Diabetic Med 1986;3:38-4I. [CrossRef]

23. Loewenfeld IE, Lowenstein O. The pupil: anatomy, physiology, and clinical applications. Ames: lowa State University Press/ Detroit: Wayne State University Press; 1993. p. 407-479, 498517, I|3|-II87, I200-1203.

24. Bourne PR, Smith SA, Smith SE. Dynamics of the light reflex and the influence of age on the human pupil measured by television pupillometry [proceedings]. J Physiol 1979;293-30I.

25. Meller J. Ueber hyaline Degeneration des Pupillarrandes. Von Graefes Arch Ophthalmol 1904;59:221-8. [CrossRef]

26. Pagani M, Lombardi F, Guzzetti S, Rimoldi O, Furlan R, Pizzinelli $P$, et al. Power spectral analysis of heart rate and arterial pressure variabilities as a marker of sympatho-vagal interaction in man and conscious dog. Circ Res 1986;59: 178-93. [CrossRef]

27. Semmlow J, Stark L. Pupil movements to light and accommodative stimulation: a comparative study. Vision Research 1973; 13:1087-100. [CrossRef]

28. Wyatt HJ. The form of the human pupil. Vision Research 1995;35:2021-36. [CrossRef] 
29. Sevilla Y, Maldonado M, Shalom DE. Pupillary dynamics reveal computational cost in sentence planning. Q J Exp Psychol (Hove) 2014;67:104I-52. [CrossRef]

30. Binda P, Murray SO. Spatial attention increases the pupillary response to light changes. J Vis 20I5; I5(2): I. [CrossRef]

3I. Mesin L, Monaco A, Cattaneo R. Investigation of nonlinear pupil dynamics by recurrence quantification analysis. Biomed Res Int 2013;2013:420509. [CrossRef]

32. Ebitz RB, Pearson JM, Platt ML. Pupil size and social vigilance in rhesus macaques. Front Neurosci 2014;8:100. [CrossRef]

33. Bieniek MM, Frei LS, Rousselet GA. Early ERPs to faces: aging, luminance, and individual differences. Front Psychol 2013;4:268. 